\title{
REPRESENTAÇÕES E ESTEREÓTIPOS SOBRE A TRADUÇÃO PORTUGUÊS/ESPANHOL
}

\author{
REPRESENTATIONS AND STEREOTYPES ABOUT THE \\ TRANSLATION PORTUGUESE/SPANISH
}

\section{Angélica Karim Garcia Simão*}

\section{RESUMO}

Pretende-se discutir a questão dos estereótipos a respeito da tradução da língua espanhola e portuguesa buscando-se problematizar a relação entre os enunciados produzidos por estudantes brasileiros, espanhóis e argentinos de diferentes contextos de formação em Tradução. Para tanto, delimitamos inicialmente o termo e o conceito de estereótipo, entendendo o segundo como uma representação - de caráter homogeneizador - atribuída à realidade, em um processo de simplificação cognitiva, e os seus desdobramentos dentro de estudos ao longo do século XX. Posteriormente, apresentamos quais são os estereótipos relacionados à tradução da língua espanhola levantados em um curso de Tradução brasileiro, Bacharelado em Letras-Tradutor, a partir de pesquisa empírica, utilizando-se técnicas desenvolvidas para realizar a análise estrutural das representações sociais. Para finalizar, contrapomos os estereótipos citados anteriormente aos enunciados sobre a tradução da língua portuguesa formulados por estudantes de tradução de língua portuguesa provenientes de dois contextos diferentes, a saber: o curso de Traductorado en Portugués (Buenos Aires - Argentina) e o curso de Traducción e Interpretación (Granada - Espanha). Os diferentes níveis de análise dos dados apoiaram-se teoricamente em trabalhos da Psicologia Social e na Semântica Enunciativa, e permitiram identificar um modo sintático-enunciativo marcado por contornos e contradições, que evitou a afirmação direta, caracterizando um dizer marcadamente polifônico, no que concerne aos enunciados brasileiros. Embora com algumas semelhanças no modo argumentativo, as representações feitas por espanhóis e argentinos se distanciam no que tange aos objetos de valoração atrelados ao idioma português.

Palavras-chave: tradução; estereótipos; espanhol

\section{ABSTRACT}

This work is aimed at discussing stereotypes in about the translation Spanish and Portuguese, seeking to problematize the relationship among utterances produced by Brazilian, Spanish and Argentine undergraduate students from different contexts of graduation in translation. In order to do so, the term and concept of stereotype were initially delimited, the latter understood as a representation that ascribes to a perspective of reality as homogeneous, in a process of cognitive simplification, and its ramifications in studies throughout the twentieth

\footnotetext{
* UNESP/SJRP, São José do Rio Preto (SP), Brasil. angelica@ibilce.unesp.br; Fapesp (Processo 2009/08115-6)
} 
century. Subsequently, based on the data collected from classes of a Translation undergraduate course in Brazil, I discuss which stereotypes are related to the translation of the Spanish language, using techniques developed to conduct the empirical and structural analysis of social representations. These stereotypes are finally compared to utterances about the translation of Portuguese language produced by students of Portuguese translation from two different contexts, namely the course Traductorado en Portugués (Buenos Aires - Argentina) and Traducción e Interpretación (Granada - Spain). The different levels of data analysis are based on theoretical works from Social Psychology and Enunciative Semantics. They enabled me to identify a syntactic-enunciative mode characterized by outlines and contradictions, which in turn avoided direct statements by Brazilian students, revealing a saying markedly polyphonic. In spite of some similarities in the argumentative mode, the representations made by Spaniards and Argentines are distant with respect to the objects of valuation embedded to the Portuguese language.

Keywords: translation; stereotypes; spanish language.

\section{INTRODUÇÃO}

O termo estereótipo, neologismo criado no século XVIII, foi utilizado inicialmente pela tipografia para designar um conjunto de modelos fixos. A palavra deriva do grego, stereós (sólido) e typos (carácter ou modelo), e aparece pela primeira vez documentada por escrito em língua portuguesa em $1836^{1}$.

Do emprego técnico, o termo derivou para o uso figurativo, e passou a referir-se a qualquer coisa que se repete sistematicamente. Na maioria das línguas, seu uso se relaciona às formas de falar, às locuções da linguagem formal ou informal, cujo emprego se intensifica, em determinadas épocas, como uma moda.

A partir do século XIX, o termo deixou de ser aplicado somente a frases e passou a referir-se também a opiniões e visões de problemas ou grupos sociais. Atualmente, além da significação relacionada às artes gráficas, o termo é entendido como tudo que se adéqua a rigidez ou invariabilidade, um padrão fixo e geral, ou a esse próprio padrão, formado por ideias preconcebidas e alimentado pela falta de conhecimento "real", se é possível afirmar que este existe, sobre o assunto em questão. Também é entendido como algo que é falso ou proveniente de falsas generalizações, um clichê ou lugar-comum, e opõe-se à ideia do que é autêntico e variado.

O conceito de estereótipo nasceu nas ciências sociais e é empregado até a atualidade com a mesma denotação. A primeira pessoa a tratar o fenômeno da estereotipia à luz da ciência social foi o jornalista norte-americano Walter Lippman em sua obra "A opinião pública", publicado em 1922, com o objetivo de esclarecer

1 Francisco Solano Constâncio. Novo dicionário critico e etymológico da língua portugueza. Paris, 1836. 
quais eram os múltiplos fatores que determinam a opinião pública nos meios de comunicação de massa. Nessa obra, o autor aplica o conceito a uma ampla quantidade de conteúdos e estabelece todas as áreas que constituirão o estudo empírico e teórico dos estereótipos, analisando-os sob três vertentes: a cognitiva, a social e a emocional.

De acordo com Mussalim \& Fonseca-Silva (2011), as ideias de Lippman sobre os estereótipos foram negligenciadas nas décadas de 30, 40 e 50 do século XX pela grande maioria das investigações empíricas que caracterizavam os estereótipos como um tipo inferior de pensamento, situando-os no domínio do patológico. Tal fato fez com que só ganhassem fôlego após a década de 50, quando passaram a ser relacionadas aos processos de categorização e às funções cognitivas e sociais.

O conceito de estereótipo atrela-se diretamente ao de preconceito, uma vez que o primeiro compõe o núcleo cognitivo do segundo. Nas palavras de Mazzara (1999, p.14), "o estereótipo é o conjunto de informações e crenças relacionadas a categorias de objetos, reelaboradas em uma imagem coerente e constante, em condição de sustentar e reproduzir o preconceito diante dos objetos". Esse autor pontua que, justamente por haver tal relação, muitas das investigações que se dedicam a explorar o tema do preconceito acabam por descrever os estereótipos comuns e a examinar o modo como orientam a percepção dos dados da realidade em direção ao preconceito, uma vez que este retira sua força do conjunto de ideias genéricas que circulam em determinada cultura sobre os objetos.

O estereótipo atravessa a questão da opinião e do sentido comum, da relação com o outro e da categorização, e permite que estudemos as interações sociais, a relação dos discursos com os imaginários sociais e, em termos mais abrangentes, a relação entre linguagem e sociedade (AMOSSY \& PIERROT, 1997/2001).

O conceito de estereótipo utilizado nesta análise apoia-se na perspectiva de Lippman $(1966 / 1972)^{2}$. De acordo com esse autor, o homem é incapaz de perceber a totalidade do meio no qual vive direta e objetivamente. O que ele vê é uma projeção da realidade ou uma representação desta, criada, em maior ou menor grau, a partir de sua própria percepção. Esse recurso é resultado de um processo de simplificação cognitiva, uma vez que o meio, em sua totalidade, é demasiado grande e complexo para ser apreendido em sua completude.

Dessa forma, para poder interagir nele e com ele, é necessário que se realize essa reconstrução, que ocorre, na maior parte das vezes, de modo fragmentado e

\footnotetext{
$2 \mathrm{O}$ artigo de Lippman foi publicado originalmente em 1922. A versão utilizada aqui é a tradução da obra de Lippman reproduzida em Mass Media and comunication, publicada em 1966, nos EUA, e em 1972, no Brasil, pela editora Cultrix.
} 
permeado por filtros culturais, individuais, sentimentais, sociais, códigos morais, filosóficos e políticos, dentre outros, além de apresentar também um elevado componente criativo. É como se o homem utilizasse peças próprias, derivadas de seu conhecimento de mundo, para completar os vãos existentes no complexo quebra-cabeça que é o objeto que vislumbra.

A partir do conceito de Lippman, procuraremos refletir neste trabalho sobre a questão dos estereótipos e das representações a respeito da tradução envolvendo o par bilíngue português e espanhol em três contextos de formação em tradução diferentes: o brasileiro, o argentino e o espanhol.

\section{ESTEREÓTIPOS SOBRE A TRADUÇÃO DO ESPANHOL}

Dos estereótipos levantados a partir da análise dos dados coletados em contexto brasileiro (questionários respondidos por estudantes de tradução de língua espanhola em contexto de formação universitária no Brasil $1^{3}$ ), pode-se verificar uma grande atenção voltada para a perspectiva de mercado de trabalho na área. Na amostra composta pelas respostas aos questionários, o termo mercado é mencionado 114 vezes, dentre elas, 75 vezes o termo integra a expressão mercado de trabalho.

Em muitos desses casos, pode-se observar a citação do MERCOSUL de forma direta, como demonstram os excertos transcritos abaixo:

- além de ser uma das línguas mais faladas no mundo, está em grande evidência no mercado, especialmente pelo MERCOSUL

- o espanhol pode abrir portas para trabalhos com comércio exterior no MERCOSUL

- imagino que o mercado de trabalho no espanhol também seja amplo devido ao MERCOSUL

- o espanhol é uma língua em que há mercado também, especialmente porque a maioria dos países das Américas fala espanhol, com o MERCOSUL esse mercado aumenta

- gostaria de trabalhar em alguma empresa que prestasse serviços para Espanha ou o MERCOsUL

- o espanhol já se tornou a língua mais estudada aqui no Brasil e talvez por essa razão, abra mais portas, não esquecendo também o MERCOSUL, que contribui significativamente

Ou é mencionado, indiretamente, por meio das expressões em destaque:

\footnotetext{
3 As técnicas empregadas para realizar a coleta de dados sobre as representações e estereótipos foram descritas em Simão (2009).
} 
- o mercado para o tradutor de espanhol deve crescer, juntamente com o crescimento econômico de países como Espanha e Argentina

- o Espanhol é mais promissor que a primeira língua (Francês), porque temos um contato mais direto com a América Latina

- a língua espanhola [...] possui um mercado em ampliação devido às relações políticas e econômicas dentro da América do Sul

- o mercado de trabalho para o tradutor parece ser promissor, especialmente nas empresas exportadoras

- oferece muitas oportunidades por estarmos na América Latina e pelas relações que mantemos com os países desta língua

- acredito que o mercado de trabalho está em expansão devido às relações econômicas do Brasil com países Latinos

Podemos notar nesses enunciados o estereótipo de que estudar a língua espanhola é visto como uma vantagem para o aprendiz. Além disso, ela também é referida como a língua de maior expansão atualmente, fator que parece ser fortemente influenciado pela crença de que o MERCOSUL é um elemento propulsor desse desenvolvimento. Apontamos então a projeção de um mercado de trabalho promissor em função do desenvolvimento do MERCOSUL como o primeiro estereótipo de estudantes brasileiros a ser contrastado com dados de estudantes argentinos e espanhóis.

Esse vislumbre de que a língua espanhola atravessa um período de bonança é reiterado pela circulação de discursos que evidenciam o crescimento e aumento de prestígio do idioma espanhol no Brasil, como se pode observar no artigo de Moreno Fernández (2005), que aponta três importantes aspectos da vida econômica, social e cultural do país que justificam esse crescimento: a criação do MERCOSUL em 1991, a implantação de empresas espanholas no Brasil, a partir de 1996, e a cultura hispânica em geral.

Como já discutimos anteriormente (Simão, 2011), sabemos que até o momento pouco foi feito em termos de políticas linguísticas em relação ao MERCOSUL, muito embora isso tenha avançado nos últimos anos. Também não se sabe até que ponto e em que medida o Mercado Comum do Sul absorve, no setor trabalhista, profissionais do campo da tradução, direta ou indiretamente, e de que forma o trabalho de tradução é organizado nessa esfera, o que sugere não existir no seio do MERCOSUL uma articulação tão clara sobre qual política linguística e tradutória orienta o planejamento das ações envolvidas no acordo.

Outro aspecto muito presente nos enunciados dos aprendizes com relação à língua espanhola, já tratados por outros autores (CELADA \& GONZÁLEZ, 2001 e 2005), diz respeito à suposta facilidade ou proximidade entre a língua portuguesa 
e espanhola que acarreta a ideia da consequente facilidade de tradução dos dois idiomas. A esse respeito Sabio Pinilla (1992, p. 616) argumenta que

A intrusão na hora de traduzir línguas afins, com relação a outras línguas mais distantes, é enorme [...] tal fato se deve, em certa medida, a pouca atenção dada ao estudo da língua portuguesa na Espanha e à falta de formação de tradutores que demonstram pouco profissionalismo ao traduzir uma língua que desconhecem amparados na enganosa facilidade com a que acreditam entendê-la.

Garcia-Medall (2000) também reforça o escasso interesse que há e sempre houve na Espanha pelos estudos linguísticos enfocando o idioma português. Em artigo posterior Sabio Pinilla (2007) aponta, novamente, certa tradição espanhola em não realizar estudos sobre as línguas consideradas "fáceis" (aspas do autor) e retoma o fato de que a aparente facilidade, produto do parentesco linguístico, atinge um nível de ousadia espantoso.

As afirmações dos autores acima parecem indicar a presença desse estereótipo também em contextos externos ao Brasil em que as línguas portuguesa e espanhola são foco de estudo e análise. Apontamos o estereótipo da suposta facilidade e proximidade como geradora da facilidade para a tradução manifestada por estudantes brasileiros como o segundo estereótipo levantado em contexto brasileiro a ser contrastado com os dados coletados em contexto argentino e espanhol.

\section{A MOBILIZAÇÃO DE IDEIAS ESTEREOTIPADAS: ORIENTAÇÃO ARGUMENTA- TIVA DOS ENUNCIADOS}

Antes de passarmos ao contraste das representações de brasileiros, espanhóis e argentinos a respeito dos idiomas português e espanhol, é importante também abordar que ao observar os enunciados da amostra coletada entre os estudantes brasileiros ficou evidenciada uma alta frequência de construções causais, adversativas e concessivas, e um movimento argumentativo polifônico. Vejamos alguns excertos que corroboram essa visão com conectores causais porque, por isso e portanto.

a. Escolhi estudar espanhol porque acho que há um amplo mercado de trabalho.

b. A grande maioria da sala não havia estudado antes espanhol, e por isso mostra grande interesse pela língua.

c. É uma língua [espanhol] em ascensão, portanto merece ser estudada devidamente. 
Montolío (2001, p. 120) adverte que o conector por isso possui um elemento claramente anafórico, isto é, que assinala um elemento informativo prévio que indica a causa desencadeante da consequência ou conclusão que aparece depois desse conector. Segundo essa autora, esse tipo de argumentação, baseado em indicar qual é a causa ou motivo relevante, deve indicar uma causa sólida, ou pelo menos razoável, do ponto de vista argumentativo. Por esse motivo, ela julga que esses marcadores constituem uma espécie de ponto intermediário entre os conectores que expressam causa, como porque, por exemplo, e os que indicam consequência, como portanto.

Desse modo, a partir da escala proposta pela autora, parece ser possível estabelecer uma gradação dos conectores no percurso de focalização, que pode ser a indicação e a focalização da causa (porque), a indicação da consequência e a focalização da causa (por isso), até a indicação e focalização da consequência (portanto).

A observação dos três enunciados nos leva a pensar em sua orientação argumentativa. Guimarães (2007), ao tratar os operadores conclusivos sem tanta especificidade e tentando estabelecer uma caracterização geral para as relações conclusivas, aponta para o fato de que a relação de orientação argumentativa entre dois elementos é uma relação constituída pela enunciação e não pela relação entre linguagem/referente, não havendo, dessa forma, uma questão relativa às condições de verdade para o uso dessas construções. Nessa relação não há um comprometimento do locutor com a verdade, e sim uma mobilização de sentidos. $\mathrm{O}$ autor demonstra que nos enunciados causais o locutor representa dois enunciadores ao apresentar explicitamente o argumento e a conclusão. Tal fato caracteriza tais construções como polifônicas.

Há ainda nessa relação argumentativa a presença de um implícito (B) mobilizado por um dos enunciadores na enunciação, uma vez que o que está explícito pelos enunciadores, argumento (A) e conclusão (C), é representado como algo geralmente aceito como possível de sustentar sua argumentação.

Guimarães (2007) apropria-se de Berrendoner (1981) para tratar esse enunciador como um enunciador genérico $\left(\mathrm{E}^{2}\right)$ cuja perspectiva é a de um conjunto razoavelmente indefinido de pessoas que apresenta certa "crença" em comum a respeito de um fato. Segundo esse autor, o locutor, em relação ao enunciador genérico, em uma situação de enunciação particular, recorta discursos diversos para preencher suas indicações, podendo haver casos em que o preenchimento se dá com recortes do discurso do senso comum. Vejamos como se dá essa relação com o seguinte enunciado sobre a língua espanhola extraído de nossos dados: 
d. O que se firmou foi a minha expectativa de poder ser intérprete, pois é uma língua mais fácil de assimilar.

É possível pensar em uma série de sentidos comuns que sustentem ou justifiquem a perspectiva de $\mathrm{E}^{1}$ e que incluem como implícito um enunciador genérico $\left(E^{2}\right)$ que postula os seguintes sentidos atrelados ao argumento é mais fácil de se assimilar: é mais fácil para aprender, é mais fácil que qualquer outro idioma (inglês, francês, italiano...), é mais fácil porque é parecido com o português, não demanda muito trabalho/empenho/estudo/dedicação, etc.

Tanto os enunciados causais como os concessivos e adversativos presentes nos dados analisados apontam para uma orientação argumentativa na qual co-existem mais de um enunciador mobilizando implícitos atrelados aos estereótipos mencionados anteriormente: o da facilidade do idioma gerado pela proximidade entre as línguas portuguesa e espanhola e o da projeção de um mercado de trabalho em expansão em função do Mercosul.

Passaremos agora a observar como estudantes de tradução de contextos espanhol e argentino representam seus estereótipos a respeito da tradução do português.

\section{REPRESENTAÇÕES SOBRE A LÍNGUA PORTUGUESA EM CONTEXTO ARGEN- TINO E ESPANHOL}

\subsection{0 contexto argentino}

Em resposta ao mesmo questionário, aplicado mediante o uso das mesmas técnicas de coleta dados em contexto de formação na carreira de Traductorado na Argentina, obtivemos um mapeamento das representações do idioma português um pouco diferentes das encontradas com relação ao espanhol no Brasil.

Observamos escassas menções à facilidade ou proximidade dos dois idiomas. $\mathrm{Na}$ prática, houve somente um único momento em que essa referência foi feita à língua portuguesa, reclamando a sua valorização no contexto argentino:

e. Me gustaría que sea revalorada, ya que debido a sus transparencias con el español muchos piensan que por dominar las dos lenguas ya están listos para traducir.

Embora nosso viés de análise não se pontue em dados quantitativos, por se tratar da manifestação de uma única crença isolada, não entendemos nessa pesqui- 
sa a ideia expressa acima como a configuração de um estereótipo partilhado pelo grupo.

De modo indireto, o estereótipo da suposta facilidade/proximidade expresso por meio da surpresa diante da dificuldade imposta ao aprendizado do idioma português, também foi manifestado uma única vez, como demonstra o enunciado abaixo:

f. [Estudié el idioma português] tres años en una institución reconocida pero me sorprendí al darme cuenta todo lo que no sé.

No entanto, o encadeamento do enunciado (d) com creo que em creo que el idioma debería ser revalorado ya que sus transparencias sugieren que están listos para traducir, temos a transparência como razão para afirmar a desvalorização do idioma português em contexto argentino. Neste caso, o desdobramento para dois locutores numa conversa torna-se possível o que revela o caráter polifônico do enunciado:

$\mathrm{L}^{1}$ - El idioma es desvalorado

$\mathrm{L}^{2}$ - Ya que sus transparencias con el español sugiere que cualquiera pueda traducir.

Do mesmo modo, as orações no enunciado (e) podem ser tomadas separadamente no encadeamento:

L1 - Estudié tres años

$\mathrm{L}^{2}$ - Pero me sorprendí con lo que no sé.

Por outro lado, a ideia de um mercado de trabalho em ascensão foi retomada várias vezes na amostra, revelando a projeção de um futuro promissor em função do MERCOSUL, como demonstram os enunciados abaixo:

- A raíz del Mercosur y de la implantación del idioma en las escuelas el idioma portugués va a ser mucho más valorado.

- Mi interés personal es alto, al igual que el mercado laboral. Hoy en día se puede vivir de la traducción.

- Espero que de una vez por todas el Mercosur comience a funcionar y así tener más trabajo. De lo contrario me iría vivir a Brasil.

- El mercado demanda traductores de portugués debido a las relaciones entre Argentina y Brasil.

- Las expectativas son las mejores. Adoro la lengua portuguesa, hay mercado de trabajo.

- El mercado laboral me parece una idea interesante a futuro. 
- Creo que el mercado necesita profesionales del área y no "nativos" o personas que vivieron en otro país y conocen algo de la lengua extranjera.

Alguma vezes o estereótipo foi retomado por meio de enunciados polifônicos em construções causais:

- Creo que es un momento propicio en el mercado de trabajo ya que hay un visible aumento en el vínculo cultural y económico con Brasil.

- Brasil está evolucionando como país, por lo tanto en unos años se volverá una potencia lo cual traerá mucho trabajo.

Embora em pequena escala, algumas asserções com movimento disfórico, revelando a falta de perspectiva com a profissão, foram observadas:

- El mercado de trabajo no es fácil ya que hay mucha competencia.

Sobre as construções com relações causais entre proposições, Neves (2000) acrescenta que nesse tipo de construção surge a questão da "realidade" ou "efetividade" da causação, na qual reside a questão de que não é o fato de dois estados de coisas serem relacionados quanto a sua relação causa/consequência que estabelece tal relação, mas sim o fato de o falante propô-los como tal. Desse modo, considerandose que a causalidade é enunciada, e não (cientificamente) comprovada, ela deve ser entendida como referente a qualquer zona que se situe no amplo espectro que vai, por exemplo, da causa eficiente, sendo esta a que liga dois eventos em subsequência temporal, à justificação, passando por relações como razão, motivo e explicação.

Não se pode buscar nos enunciados a pura ordenação lógica ou cronológica de eventos, já que, por definição, cada enunciado constitui uma versão particular - com base cognitiva - da organização dos fatos. Na construção causal com o enunciado de fatos possíveis por um falante, a ordem se subordina à escolha que esse falante faz da apresentação dos fatos, o que reflete não apenas a percepção dos eventos, mas, ainda, a organização de uma porção de fala particular dentro da qual o aspecto cognitivo é apenas um dos componentes, subordinados à intenção comunicativa.

O estudo das construções causais correntes de uma língua não pode governar-se pelos esquemas lógicos. Tal estudo abriga a investigação de domínios envolvidos na produção dos enunciados. Ao lado da reflexão sobre os esquemas lógico-semânticos implicados na relação causal, buscou-se uma definição pragmática dos enunciados que se constroem sobre essa relação (Neves, 2000, p. 494). 
As marcas da polifonia também se fizeram visíveis em construções adversativas, como podemos observar nos enunciados abaixo, com movimento ora eufórico, ora disfórico:

g. Hay mi interés personal pero no descarto que con el Mercosur haya una eventual salida laboral interesante.

h. Sé que el mercado es pequeño, pero creo que existen posibilidades si uno trabaja con seriedad.

i. Cuando ingresé en la carrera tenía más expectativa de trabajo, pero ahora creo que bajó bastante.

j. Sé que hay bastante demanda de personas con idioma portugués pero no tanto para traductorado pero como es algo que me gusta no me molesta.

Ao contrapor os conectores pero e aunque, da língua espanhola, mas e embora do português, respectivamente, Montolío (2001) propõe que o argumento que o conector adversativo mas introduz, é o que se impõe, apresentando-se como o argumento mais forte do ponto de vista argumentativo.

Dessa forma, ela expressa do seguinte modo a articulação desses dois conectores com os enunciados que propõem:

$<\mathrm{A}$, mas $\mathrm{B}>=\mathrm{B}$ ganha, pois se apresenta como argumento mais forte

$<\mathrm{A}$, embora $\mathrm{B}>=\mathrm{B}$ perde, pois se apresenta como argumento mais fraco

Do mesmo modo, Guimarães (2007) argumenta que o funcionamento do mas envolve um desdobramento de vozes ligadas à presença obrigatória da negação polêmica que aparece na primeira parte da frase, explicando que na orientação argumentativa o texto progride levando em conta a direção indicada pelo segundo argumento (B).

$\mathrm{O}$ autor considera a polifonia da enunciação presente nesse tipo de enunciado, uma vez que o locutor estabelece com seu alocutário um lugar e se opõe a ele em seguida. Dessa forma, as construções adversativas revelam a contradição dentro dos próprios enunciados, evidenciando as discrepâncias presentes nas oposições dos argumentos propostos. Nos enunciados citados anteriormente, temos então:

k. interesse pessoal versus mercado de trabalho

1. restrição de mercado versus empenho pessoal

m. alta expectativa versus baixa expectativa

n. grande procura pelo português versus baixa procura pelo profissional de tradução versus gosto pela profissão. 
Tais enunciados acabam por revelar uma relação contraditória com os objetos aos quais se referem, uma vez que são marcados por um modo argumentativo caracterizado por contornos e evasões.

\subsection{0 contexto espanhol}

O contraste entre os conectores pero e aunque torna-se também pertinente para a análise dos dados do contexto espanhol, uma vez que esses conectores, sobretudo aunque, foram observados com muita frequência, como demonstram os enunciados abaixo:

o. En España es más frecuente que la gente hable o entienda el portugués pero por otra parte hay menos personas capaces de llevar a cabo la profesión de traductor.

p. No pensaba que la LP fuese a formar parte de mi futuro pero cada vez me gusta más y cada vez pienso más en esa idea.

q. Evidentemente no es como traducir ruso o chino, pero se necesita una formación muy completa para llegar a traducir.

r. Con la UE creo que mejorará su posición en el mercado aunque Brasil sea el de mayor dimensión.

s. La verdad es que me gustaría poder dedicarme a la traducción/interpretación de este idioma, aunque no creo que haya muchas salidas pero tampoco mucha competencia en el mercado laboral.

t. Me gustaría enfocar mi formación en traducción de la lengua portuguesa hacia la traducción literaria, aunque sé que hay más trabajo de traductor jurado.

u. Creo que aunque el mercado de trabajo no es muy grande, al no existir muchos traductores o interpretes de portugués, seguro que habrá trabajo.

A referência a proximidade ou facilidade do idioma português em contexto espanhol também não se configurou como um estereótipo sedimentado, tal qual ocorreu em contexto argentino, uma vez que não foi compartilhado massivamente pelo grupo, embora tenha se insinuado em alguns enunciados direta ou indiretamente, como se pode observar no enunciado (j) e nos enunciados abaixo:

- Además hay pocos traductores e intérpretes de portugués que sean realmente buenos. Esto ocurre porque se cree que todo el mundo puede traducir portugués, porque tiene similitudes con el español.

- Depende del país donde se realiza la práctica traductora ya que en España es más frecuente que la gente hable o entienda el portugués. 
Entretanto, a projeção de um mercado de trabalho amplo em função do desenvolvimento brasileiro também se manifestou nesse contexto, com expresso no enunciado (m) e também abaixo.

- Creo que el portugués es una lengua que cobra cada vez más importancia debido al desarrollo de Brasil y por eso me parece útil.

- Espero que pueda tener alguna relevancia en organismos internacionales por la importancia de Brasil.

Esse argumento opõe-se a escassez de profissionais na área manifestada em algumas proposições:

- Espero poder dedicarme a esto ya que hay pocos buenos traductores de portugués

- Creo que no me resultará difícil dado que se basa en un mercado de trabajo exclusivo.

Nessa perspectiva, a falta de interesse pela língua portuguesa atrelada à escassez de profissionais que se dedicam ao idioma parecem impor-se como argumento que justifica a falta de valor ou prestígio que o idioma português adquire nesse contexto, sobretudo quando comparado a outros idiomas. Daí alguns argumentos compensatórios (inclusive) serem introduzidos, associados à dúvida (talvez) e à contradição (apesar):

- Penso que hoje em dia todas as línguas são importantes inclusive o português.

- Penso que apesar do português também ser importante, nem toda a gente segue por essa vertente, talvez porque pensem que esta língua não os ajudará na sua vida futura, tal como o inglês ou o francês.

Também nos dados coletados em contexto brasileiro pode-se observar a presença de enunciados com movimentos eufóricos e disfóricos do ponto de vista semântico, além da contradição reforçada pelos conectores, o que revelou um movimento de afastamento/aproximação e de valoração positiva ou negativa, dos idiomas aos quais se referiam.

\section{CONSIDERAÇÕES FINAIS}

No contexto argentino pudemos constatar a presença de uma visão ufanista com relação à projeção de um mercado de trabalho promissor em função do MERCOSUL. No contexto espanhol, a ideia do desenvolvimento e do crescimento eco- 
nômico brasileiro configurou-se também como um estereótipo compartilhado pelo grupo, o que coloca tal representação como um elemento comum aos três contextos. Embora assentados em bases argumentativas diferentes, a manifestação de tais estereótipos foi, nos três âmbitos investigados, expressa de modo semelhante: pelo excesso de construções causais, concessivas e adversativas.

No contexto argentino, o mercado brasileiro é apontado de modo mais eufórico e positivo, mesmo quando aparece dissociado da ideia do MERCOSUL. Não queremos afirmar com isso que os sujeitos envolvidos em contextos de formação acadêmica de um ou outro país sejam mais ou menos otimistas ou pessimistas com relação às realidades trabalhistas dos países vizinhos, porém apresentam em seus enunciados movimentos argumentativos que revelam a valorização/desvalorização desses contextos em função de suas percepções e representações das realidades sobre as quais se manifestam.

Notamos também que a presença do estereótipo da facilidade e proximidade entre os dois idiomas, embora seja insinuada nos contextos externos, aparece de modo menos enfático do que nos enunciados produzidos em contexto brasileiro.

Embora nossa análise seja de caráter qualitativo e não se preste a generalizações, podemos concluir que há um ponto característico nas amostras dos três contextos investigados (brasileiro, argentino e espanhol): o dizer marcado por um movimento argumentativo caracterizado pelo contorno e pela contradição, um jogo de vaivém que ora valoriza ou aproxima os objetos avaliados, ora os desvaloriza ou distancia, enunciados polifônicos que revelam as múltiplas vozes presentes nesses contextos.

A esse respeito, é interessante retomar a problematização feita por Coracini (2005) em torno das representações e dicotomias que perpassam a constituição da subjetividade do tradutor. A autora, que assume um escopo teórico diferente do trabalho que apresentamos aqui, pois parte das teorias da psicanálise e do discurso, chama o discurso dos tradutores de discurso da dúvida, retomando a angústia da dívida à qual o tradutor se sente submetido, sobretudo, em se tratando da dicotomia teoria e prática tradutórias. No entanto, ela também não se esquece das outras várias tensões às quais se submetem diariamente os tradutores: o encontro entre as línguas, a hierarquia original versus tradução, a impossibilidade da tradução perfeita e fiel ou a idealização da suposta fidelidade... o que talvez justifique esse dizer assentado nos desvios e que se nega a estabelecer limites precisos. 


\section{REFERÊNCIAS BIBLIOGRÁFICAS}

AMOSSY, R. e PIERROT, A. H. (1997/2001). Estereotipos y clichés. Trad. Lélia Gandara. Buenos Aires: Eudeba.

CELADA, M. T.; GONZÁLEZ, N. M. (2001). El contrapunto de dos lenguas: Los argentinos somos así. Brasileiro é assim mesmo. Revista Eletrônica ELE da Editora Espasa Calpe, v. 1. Seção Investigación.

CELADA, M. T.; GONZÁLEZ, N. M. (2005). El español en Brasil: un intento de captar el orden de la experiencia. In: Sedycias, J. (Org.) O ensino do espanbol no Brasil: passado, presente e futuro. São Paulo: Parábola, pp. 71-96.

CORACINI, M. J. R. F. (2005). O Sujeito tradutor: entre a sua língua e a língua do outro. Cadernos de Tradução (UFSC), v. XVI, pp. 09-24.

GARCIA-MEDALL, J. (2000). Traducción portugués-español: lagunas y perspectivas. Hermeneus. Revista de Traducción e Interpretación. n. 2, pp. 1-18.

GUIMARÃES, E. (2007). Texto e argumentação: um estudo de conjunções do português. 4 ed. Campinas: Pontes.

LIPPMAN, W. (1966/1972) Estereótipos. In: Steinberg, C. S. (Org.) Meios de Comunicação de Massa. Trad. Otávio Mendes Cajado. São Paulo: Cultrix, pp. 151-168.

MAZZARA, B. M. (1999). Estereotipos y prejuicios. Madrid: Acento Editorial.

MONTOLÍO, E. (2001). Conectores de la lengua. Barcelona: Editorial Ariel.

NEVES, M. H. M. (2000). Gramática de usos do português. São Paulo: Editora Unesp.

MUSSALIM, F.; FONSECA-SILVA, C. (2011). Estereótipos de gênero e cenografias em anúncios publicitários. In: Motta, A. R. \& Salgado, L. Fórmulas discursivas. São Paulo: Editora Contexto, pp. 139-150.

SIMÃO, A. K. G. (2009). Traduzir a língua espanhola no Brasil: estereótipos sobre a proximidade e o MERCOSUL. Digilenguas, v. I, n. 3, pp. 291-301.

SIMÃO, A. K. G. (2011). A dimensão estrangeira da tradução da língua espanhola no MERCOSUL. In-Traduções, v. 1, pp.49- 58.

SABIO PINILLA, J. A. (1992). Traducir del portugués al español: la engañosa facilidad. In: Edo Julià, M. (ed.). Actes del I Congrés Internacional sobre Traducció, vol. II, Barcelona, UBA, pp. 613-20.

SABIO PINILLA, J. A. (2007). Hierarquía lingüística e tradução entre línguas próximas. Mundo Eslavo: Revista de cultura y estudios eslavos. v. I, n.6, pp. 207-219.

Recebido: 03/05/2013

Aceito: 18/04/2014 